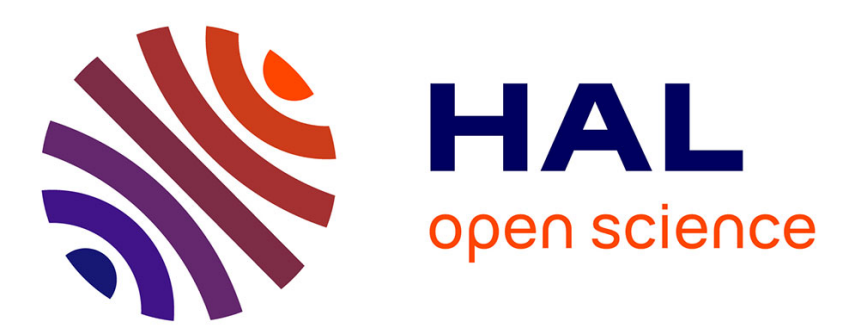

\title{
From burlesque to horror: a century of sleepwalking on the silver screen
}

Marie-Amelie Dalloz, Klara Kovarski, Ruben Tamazyan, Isabelle Arnulf

\section{To cite this version:}

Marie-Amelie Dalloz, Klara Kovarski, Ruben Tamazyan, Isabelle Arnulf. From burlesque to horror: a century of sleepwalking on the silver screen. Sleep Medicine, 2021, 85, pp.172-183. 10.1016/j.sleep.2021.07.015 . hal-03360085

\section{HAL Id: hal-03360085 \\ https://hal.sorbonne-universite.fr/hal-03360085}

Submitted on 30 Sep 2021

HAL is a multi-disciplinary open access archive for the deposit and dissemination of scientific research documents, whether they are published or not. The documents may come from teaching and research institutions in France or abroad, or from public or private research centers.
L'archive ouverte pluridisciplinaire HAL, est destinée au dépôt et à la diffusion de documents scientifiques de niveau recherche, publiés ou non, émanant des établissements d'enseignement et de recherche français ou étrangers, des laboratoires publics ou privés. 


\section{From burlesque to horror: a century of sleepwalking on the silver screen}

Marie-Amelie Dalloz, $\mathrm{MD}^{1}$, Klara Kovarski, $\mathrm{PhD}^{2,3}$, Ruben Tamazyan, $\mathrm{MD}^{4}$, and Isabelle Arnulf, $\mathrm{MD}, \mathrm{PhD}^{1}$

${ }^{1}$ Sleep Disorder Unit, Pitié Salpêtrière Hospital, Sorbonne University, Paris, France

${ }^{2}$ Université de Paris, CNRS, Integrative Neuroscience and Cognition Center, F-75006 Paris, France

${ }^{3}$ Hôpital Fondation Rothschild, Institut de Neuropsychologie, Neurovision et NeuroCognition, Paris, France.

${ }^{4}$ Department of Neurology and Stroke Unit, Fondation Hôpital Saint-Joseph, Paris, France

Corresponding author: Isabelle Arnulf

Service des pathologies du sommeil

Hôpital Pitié-Salpêtrière

47-83 boulevard de l'Hôpital

75013 Paris, France

Phone: 33142167702

Fax: 33142167700

Email: isabelle.arnulf@aphp.fr

Competing interest: the authors have no competing interest. 


\begin{abstract}
Background: Long before being described as a disorder, sleepwalking was considered as a mysterious phenomenon inspiring artwork. From the early beginning of cinema, sleepwalkers were shown to populations, playing a crucial role in storytelling and collective knowledge.

Objective: We characterized how sleepwalking has been portrayed in a large number of movies from the origins of cinema to recent years.

Methods: Movies containing the words "sleepwalking" or "somnambulism" were searched for in International Movie Databases. Types of movies, sleepwalking characters, postures and behaviors during episodes, triggers, and suggested treatments were collected.

Results: Production of 87 movies and 22 cartoons portraying sleepwalkers was clustered around two peaks, in the 1910s and 2010s. Comedies predominated before 1960, and thriller/horror movies as a dominant genre after 1960. In contrast with real-life sleepwalking epidemiology, sleepwalkers are more often portrayed as women than men (and often wearing a transparent white nightgown), as adults more than children on-screen, and $23 \%$ suffered psychiatric comorbidities. The unrealistic posture of outstretched arms and eyes closed was found in $20 \%$ of movies and $79 \%$ of cartoons. Night terrors, sexsomnias (kissing, having sex, initiated pregnancy), sleep-related eating and sleep driving were also featured. Homicides and falls while sleepwalking were recurrent fear-inducing topics. The first sleep EEG was featured in a sleepwalking movie in 1985, and a sleep specialist gave his first advice in 1997.

Discussion: The representation of sleepwalking on the screen seems to have evolved from popular, unrealistic stereotypes of somnambulism towards a medical condition, paralleling the development of sleep medicine.
\end{abstract}

Key-words: sleepwalking; somnambulism; parasomnia; movie; cinema; film 
"Somnambulism, noctambulism, there are a lot of names for that. No cure. Good night" in Without love (H.S. Bucquet, 1945)

\section{Introduction}

Somnambulism (or sleepwalking) is a parasomnia of-primarily emerging from N3 sleep. Patients open their eyes, may sit in bed, speak (and answer questions), stand up, quietly walk and manipulate objects or on the contrary run out of bed in great distress, in a form often mixed with sleep terrors in adults [1]. However, this apparently awake behavior is accompanied by inappropriate or absent responsiveness to other's efforts to intervene, mental confusion and a partial, retrograde amnesia [2,3]. The mental content associated with the behavior is rarely reported, and contains usually a brief visual scene (often a misfortune), which is congruent with the observed behavior $[4,5]$. Sleepwalking episodes are often reported to sleep specialists by the family or by the sleepwalker as retrospective tales resembling film scenarios. In videopolysomnography (using infrared video and audio recording, leading to black and white video recordings), wandering is rare, whereas behavioral episodes are often restricted to repeated but brief confusional arousal behaviors emerging from N3 (patients open their eyes, look around, stare, speak, and sometimes sit and look confused) [1, 6]. Sleepwalking episodes can also be captured via home video with real-life lengthy video recordings [7].

Before being described as an arousal disorder, sleepwalking was long considered a mysterious phenomenon, inspiring fictional production. The sleepwalker is a recurrent figure in literature, from German romanticism in the late $18^{\text {th }}$ century (e.g., Von Kleist in The Prince of Hombourg) to the end of $19^{\text {th }}$ century (e.g., Poe, Gautier, de Maupassant, Meyrinck), when witchcraft and supernatural events were still attributed to superstitions. During this period, natural somnambulism was differentiated from the magnetic somnambulism (also named hypnosis, mesmerism and animal magnetism), popularized from the late $18^{\text {th }}$ century as a trance status induced by a an external person [8]. This fascinating character was also present in many theater plays and operas, including two emblematic female characters, i.e., Amina in La Somnambula from Bellini (1831), and Lady Macbeth represented as guilty with bloodied hands in Macbeth from Verdi (1846), based on Shakespeare's tragedy (1623) [9, 10]. Later, the popular conception of witches and ghost-like phantoms wandering at night was gradually enlightened by more rational explanations. From a mystical approach [11], sleepwalking gained a psychoanalytic aura at the end of the $19^{\text {th }}$ century, when the subconscious was considered responsible for sleepwalkers' actions $[12,13]$.

At the beginning of the $20^{\text {th }}$ century, film became a new powerful and popular artistic medium, in which sleepwalking was viewed as resulting from or being related to hypnotism or 
mesmerism. Cinema reaches large numbers of individuals, and plays a crucial role in storytelling, in creating compelling visual representations and in contributing to collective imagination. Movies have often portrayed characters with dramatic or misunderstood conditions, including psychological, psychiatric and neurological disorders (e.g., epilepsy, coma). From the very first representations, sleepwalking has been portrayed in many movie genres including dramas, comedies and cartoons, thus attaining an audience of various ages. Previous studies have investigated how cinema portrayed epilepsy [14], coma [15], and rapid eye movement sleep behavior disorder (RBD) in Disney movies [16], but no research (to our knowledge) has yet investigated how sleepwalking has been represented as a condition throughout cinematic history.

How a given disease is portrayed in movies provides a snapshot of the popular representation of a disease in a given period. The depiction can be accurate, or may on the contrary convey an unrealistic representation, thus affecting how a medical condition is understood, possibly creating and maintaining biases and stereotypes. Here, we aimed at characterizing the depiction of sleepwalking in movies over a century, from its early origins to 2019, categorizing the films, identifying differential diagnoses, describing the sleepwalkers' characters, identifying predisposing factors, priming and precipitating episodes, timing, postures (especially popular representations) and behaviors during episodes, as well as the clinical management of sleepwalkers. By characterizing and describing how various key aspects of sleepwalking, including behavioral, psychological and treatment facets are depicted across a century, we aimed at drawing parallels with common and evolving societal conceptions of the disorder, as well as comparing and contrasting these observations with current medical knowledge of the disorder.

\section{Methods}

\subsection{Selection of movies}

Movies were identified via multiple searches. The terms "sleepwalking" (French: "somnambulisme"), "somnambulism" and "sleepwalker" (French: "somnambule") were used as keywords in major internet-based movie databases International Movie Database (IMDb, https://www.imdb.com) and Rotten Tomatoes (http://rottentomatoes.com), as well as on the English and French-language versions of the Wikipedia website (fr.wikipedia.org), Senscritique (www.senscritique.com) and Vodkaster (www.vodkaster.com). We also performed a search on national film catalogues in French, English, German, Spanish, Italian, Russian and Korean. Movies were then classified into fantasy, comedy, drama, thriller and 
horror according to their main category. They were categorized as black-and-white or colored, and as silent or sound feature films. Movies including the words "sleepwalking" and "sleepwalkers" in the title, but not portraying any sleepwalking character were excluded from the analyses. The number of cartoons and episodes in TV shows representing sleepwalking episodes was high, potentially biasing the analysis. They were therefore not included, but, because of their great interest, a pool of cartoons $(\mathrm{N}=21)$ was studied in a qualitative fashion, and the representation of sleepwalking was compared in stories geared towards children and the elderly. All available movies were viewed for information extraction. If a movie was not available for viewing (e.g., old movies), it was excluded from analyses except when the script or an exhaustive summary was available (e.g., online, French National Library).

\subsection{Collection of information}

The release date and country where the movies were produced are shown in Table 1. Two independent scorers (MAD and RT) determined if sleepwalking was the main topic, a pivotal or an anecdotal scene of the movie. Several features were considered, including number of scenes representing a sleepwalker and sleepwalker characteristics (nationality, gender, age category, psychiatric comorbidities, and family history of arousal disorders). Based on the complete scenario and script, two sleep specialists (MAD and IA) identified whether sleepwalking corresponded to natural somnambulism (apparently authentic cases of sleepwalking), SRDD magnetic (hypnosis-induced trance) or feigned (malingering) somnambulism. Interscorer concordance was 100\%. The location (indoor or outdoor, in bed or not) and timing (nighttime or daytime, or exact timing when explicit) of the sleepwalking episode were collected by MAD and IA. The behavior of the sleepwalker was characterized by observing the eyes (closed or open) and arm posture (outstretched or not). We categorized whether the behavior was quiet or agitated, what actions the sleepwalker performed (ordinary or unusual), how the episodes ended (full awakening, going back to bed accompanied or not by someone) and if the behavior was dangerous for themselves and for others. We evaluated sleep mentation associated with the episode (dream, nightmare) and whether the sleepwalkers recalled their behavior afterwards. The occurrence of other sleep comorbidities (sleep talking, sleep terror, sleep-related eating behavior and sexsomnia) and triggering factors (stress, psychotrauma, sleep deprivation, alcohol intake) as well as fantasy causes (ghost possession) were described. In terms of clinical management, we noted whether a medical doctor, psychiatrist, psychologist, psychoanalyst or another caregiver was involved and if the sleepwalkers received any advice, drugs or other therapy. 


\subsection{Statistical analysis}

Most information was reported as number and percentages. Between-groups differences (e.g., percentage of movies featuring sleepwalking as humorous before and after 1960, or featuring sleepwalking episodes with eye closed vs. open) were compared using a Fisher test.

\section{Results}

\subsection{Film selection}

In the following section the name of the director was reported only for the first occurrence or to distinguish movies with homonymous titles. We found 93 movies using the searching words, but excluded 6 that did not feature any sleepwalking episode. Among the 87 movies featuring sleepwalking characters from 1903 to 2019, 42 (31\%) mentioned the term "sleepwalking" or "sleepwalk" in the title. The movies were produced in the USA $(N=39)$, France $(N=15)$, Canada $(\mathrm{N}=4)$, Germany $(\mathrm{N}=4)$, Italy $(\mathrm{N}=4)$, UK $(\mathrm{N}=3)$, Spain $(\mathrm{N}=2)$, whereas only one movie was produced in Australia, Brazil, Belgium, Columbia, China, South Korea, India, Norway, Portugal, Russia, Sweden, Switzerland, Venezuela, or Yugoslavia. One movie involved a collaboration between France and Portugal, and one other stemmed from a collaboration between France and Canada. The histogram of movies showed two main peaks of production, in the 1910-1919 and 2010-2019 decades (Figure 1). Thirty-one movies were silent movies and 56 included sound. The movies were shot in color $(\mathrm{N}=52,59.8 \%)$ and blackand-white $(\mathrm{N}=35,40.2 \%)$. Main genres included comedy $(\mathrm{N}=30,34.5 \%)$, drama $(\mathrm{N}=20$, $23 \%)$, horror $(\mathrm{N}=18,20.7 \%)$, thriller $(\mathrm{N}=14,16.1 \%)$, fantasy $(\mathrm{N}=3,3.4 \%)$ and two $(2.3 \%)$ movies were considered as experimental. Movies associated with positive emotional valence (e.g., comedy) were more often released prior to $(\mathrm{N}=26 / 43 ; 61 \%)$ rather than after $1960(\mathrm{~N}=$ $6 / 44 ; 14 \%, \mathrm{P}<0.001)$. An opposite pattern was observed for movies associated with negative emotional valence (e.g., thriller, horror), including 38\% released prior to and 80\% after 1960 $(\mathrm{P}<0.001)$. Sleepwalking was the main topic in 60/87 (69\%) movies, played an important role in $14(16 \%)$ movies and was anecdotal in $13(15 \%)$ movies. There were 1 (in 53 movies) to 6 sleepwalking episodes per film. Overall, 153 sleepwalking episodes were analyzed. Sixty-five movies were fully viewed, and in the remaining 22 movies, an exhaustive summary or script was available (leading to some missing data for the exact description of the sleepwalker).

\subsection{Characteristics of sleepwalker characters}


Most movies featured a unique sleepwalking character, except for 5 movies. In the final scene of Carmela é una Bambola (Puccini, 1958), for example, all women in town pretend to sleepwalk. In Slumber (Hopkins, 2017), a whole family of sleepwalkers is portrayed and the sleep specialist in charge of the family, who sleepwalks too, has a brother who died sleepwalking as a child. Among the 82 films featuring unique sleepwalkers, 29 (35.4\%) are men and $53(64.6 \%)$ are women. Sleepwalkers are mainly adults $(\mathrm{N}=73)$ and include young adults $(\mathrm{N}=49)$, of uncertain but adult age $(\mathrm{N}=37)$, middle age $(\mathrm{N}=11)$, and old age $(\mathrm{N}=1)$. More rarely, children $(\mathrm{N}=12)$ and adolescents $(\mathrm{N}=4)$ are depicted. The familial component of sleepwalking was present in 3 movies. In Boniface sleepwalker (Labro, 1951), the sleepwalker is featured with his children, all sleepwalking on a roof, including the baby sleeping with outstretched arms in his pram (Figure 2). In Half Angel (Sale, 1951), the father reveals to his daughter that her mother was a sleepwalker too. In The Sleepwalker Killing (Cosgrove, 2004), family history of sleepwalking is used by the expert in the criminal inquiry as evidence for a sleepwalking case. In Slumber (2017), the sleepwalking family aspect is represented as a familial evil possession. Sleepwalkers with co-occurring psychiatric symptoms (preexisting or appearing during the movie) were found in $20(23 \%)$, movies including anxiety $(\mathrm{N}=4)$, depression $(\mathrm{N}=3)$, but also posttraumatic stress disorder, maniac or psychotic disorder, and addiction (sex addiction, toxicomania).

\subsection{Differential diagnoses of sleepwalking}

Somnambulism appears to be a genuine condition in 58/87 (66.6\%) movies. The sleepwalking episode occurs within a dream in two feature films (Casey dreams that he's a sleepwalker, 1904; Sleepwalker by Runeborg, 2000). Some cases of depicted sleepwalking, however, met the criteria of differential diagnoses. These include sleep-related dissociative disorders (SRDD, N =16), malingering $(\mathrm{N}=7)$, REM sleep behavior disorder and parasomnia overlap disorder $(\mathrm{N}$ = 1), automatism-amnesia syndrome (triggered by use of psychotropic drugs, mainly benzodiazepines and $\mathrm{z}$ drugs, $\mathrm{N}=5$ ), post-traumatic sleep disorder with parasomnia (not found), and sleep-related hyperkinetic epilepsy (not found).

\subsubsection{Sleep-related (psychogenic) dissociative disorders}

SRDD are parasomnia mimics with violent behaviors (often associated with self-mutilations). They emerge from well-established wakefulness, are observed during daytime, and often (92\%) occur in a context of abuse or other trauma [17]. In movies, several sleepwalking scenes may meet these criteria, including hypnotic-induced ambulation and behaviors as well as behaviors 
triggered by evil possession, displaying amnestic victims wandering at night. In 5 movies, sleepwalking episodes are due to "magnetic" somnambulism or to the sleepwalker being in a hypnotic trance. The character of a "psychic sleepwalker" is represented in Eloi wants to learn to swim (Carré, 1910), The sleepwalking hussar (1910) and Penard is superstitious (1912). In Nick Winter and the somnambulist thief (Gorieux, 1911), the daughter's character is a sleepwalking thief under hypnotic influence, similar to The cabinet of doctor Caligari by Wiene (1920) where Cesare, a music-hall actor, kills individuals after having been hypnotized by Doctor Caligari (Figure 2). Apart from hypnosis-induced behaviors, other elements also suggest SRDD in movies. In City of Pirates (1984), the wandering character only has episodes during daytime (one leading her to murder), suggestive of SRDD. The concept of being "possessed" or under the influence of an evil character is portrayed in several films, mostly within the horror genre. The series of Dracula movies, including Nosferatu (1922), Dracula (1931), Count Dracula (1970) and Nosferatu the Vampyre (1979), portray women wandering during the night under the influence of Dracula. In Neel Kamal (1968), the main female character is called on by her former, deceased lover during wandering episodes. In Poltergeist (1982), paranormal ghosts manipulate a young girl wandering during the night. In Silent hill (2006), the ghost of a dead woman calls on a wandering girl. In Sleepwalker (2012), the character wandering during the night is possessed by the ghost of his grand-mother (who was a witch), and has during daytime personality disorders. In The conjuring (2013), a young girl who hits her head while night walking is possessed by the house ghost. In Honeymoon (2014), a naked female character is found wandering in the forest during the night, whereas it is later suggested in the movie that she had been attracted by a strange moving light. In Slumber (2017), an evil spirit possesses the character depicting the son and manipulates the whole family to the point that they all night walk. In Sleepwalker (2017), a sleepwalking woman also has daytime amnesia and lapses suggestive of a dissociative state. In Good manners (2018), a woman wandering at night is pregnant with a werewolf, and exhibits blood thirst during the full moon. In Brightburn (2019), the evil extraterrestrial main character levitates, sleep talks and displays violent behaviors.

\subsubsection{Malingering}

Feigned sleepwalking is featured in 7 movies, often related to a specific purpose (romance, masking a crime, avoiding school or making fun of a true sleepwalker). In Bébé sleepwalker (1911), the young boy simulates sleepwalking to avoid school. In Boirot sleepwalker (1915), the character feigns a sleepwalking episode during a collective hypnosis session, and takes this opportunity to slap the men and kiss the women. In the Haunted house (1928), Don't look 
now...we're being shot at! (1966) and Somnambulism and chloroform (1915), the main male character feigns a sleepwalking episode in order to go into his girlfriend's room. In Arsene Lupin (1932), two cases coexist, one with true and one with feigned sleepwalking. In Side effect (2013) the female character simulates depression to be prescribed antidepressant drug Ablixa (after reading that the drug could trigger sleepwalking), then masquerades as a sleepwalker and kills her husband, with the aim of being later declared not guilty.

\subsubsection{Drug- or substance-induced automatism-amnesia syndrome}

It can be difficult to distinguish drug-induced automatism-amnesia syndrome from a genuine sleepwalking condition in which the drug triggered or prolonged the episode and associated confusion. This is the case for alcohol, Halcium (an unknown drug) in Sleepwalker by Runeborg (2000), as well as drugs or poison given by husbands to their wives as in Sleep my love (1948) and I'm so excited (2013).

\subsubsection{REM sleep behavior disorder}

In movies, RBD was not found, but this may be due to a selection bias as we selected patients who walk during the night, whereas individuals with RBD rarely walk during RBD episodes unless they suffer from a parasomnia overlap disorder. Interestingly, in Sleepwalk with me (2017), the director and main character Mike Birbiglia portrays a medical doctor explaining that he suffers from an RBD condition (because he enacts mostly detailed nightmares), despite his young age of 30, wandering with eyes half closed, knocking on doors, jumping out the window, climbing on a piece of furniture (he dreams of standing on a podium), going in the bathroom and taking a shower, all behaviors which are more typical of sleepwalking than of RBD. However, at the end of the movie, he treats his condition by sleeping in a sleeping bag with mittens so he is unable to open the sleeping bag, and is then depicted as kicking and punching, lying down and with eyes closed, more similar to a RBD episode and suggestive of parasomnia overlap disorder.

\subsubsection{Other differential diagnoses}

We were unable to locate any sleep hyperkinetic epilepsy which may have been depicted as sleepwalking. Additionally, although some sleepwalkers started to sleepwalk after a traumatic event (e.g., in La Sirga, 2012 where the main character sleepwalks after her village was burnt), we could not find any behavioral events during the night that reproduced these traumatic events in any of the movies. 


\subsection{Location and timing of the sleepwalking episodes}

At the beginning of the episode, characters are usually asleep in their bed (or alternatively in a coach, plane seat, or coffin), or they are already standing in their bedroom $(\mathrm{N}=50)$. In 46 scenes, the sleepwalker sleeps before the episode begins. Then, the sleepwalker goes out through the house door or a window $(\mathrm{N}=52)$, walks on a roof $(\mathrm{N}=11)$, and enters the neighbor's or a stranger's house $(\mathrm{N}=21)$. Episodes take place in a context of romance $(\mathrm{N}=$ $10)$, robbery $(\mathrm{N}=5)$ or murder $(\mathrm{N}=6)$. The sleepwalker walks downtown $(\mathrm{N}=13)$ or in a natural environment ( $\mathrm{N}=14$, e.g., a forest in The Prince of Homburg by Bellocchio, in 1997, or a cemetery in the Count Dracula and In my sleep). The episode usually occurs during the night, except in 5 atypical cases. For example, in Caught in the rain (Chaplin, 1914), a woman sleepwalks in a hotel during daytime and is found sitting on a vagrant's bed. In High and dizzy (Lloyd, 1920), the character sleepwalks on a cornice. While male sleepwalkers wear underwear or pajamas, female sleepwalkers regularly wear a white nightgown $(\mathrm{N}=25)$, often transparent. Both men and women are barefoot. Two female sleepwalkers, including Lady Macbeth in Macbeth (Polanski, 1971) and Carol in A lizard on a woman skin (Fuci, 1976) are fully naked. The timing of the episode was apparent in 11 movies (visible on a clock or overtly mentioned by characters), including 4 episodes beginning during the first third of the night, 7 in the middle ( 2 to $5 \mathrm{AM}$ ) of the night and only one episode during morning awakening.

\subsection{Sleepwalking posture, eyes and gaze}

In most cases $(\mathrm{N}=52 / 65,80 \%)$, arms are down, in a neutral posture, often with a loss of passive dangling (Figure 2A). In other cases, the film director portrays the popular representation of sleepwalking with outstretched arms $(\mathrm{N}=13,20 \%)$, more often observed in comedies $(\mathrm{N}=9)$ than in drama/horror movies $(\mathrm{N}=4)$. Hands may be raised vertically, horizontal or downwards (Figure 2B). In sleepwalkers with outstretched arms, the rigid outstretched position is loosened when sleepwalkers open a door or use their hands to perform an action. Some characters stop the outstretched arm posture when they resume walking. Eyes are open when sleepwalking in $58 / 65(89.2 \%)$ movies, closed in $6(9.2 \%)$ movies and half-closed in one $(1.5 \%)$ movie (Figure 2B). In movies where eyes are clearly focused on, sleepwalkers stare wide-eyed, as in The Cabinet of Doctor Caligari (1920, Figure 3) or present an empty gaze (as in Phenomena, in 1985, Figure 2B).

\subsection{Behaviors during the parasomnia episodes}


Parasomnia behaviors are most often quiet $(\mathrm{N}=57 / 65)$. Eight episodes are mixed (quiet and agitated). In Step Brothers (2008), two sleepwalking brothers violently throw their father from the stairs. In The cabinet of doctor Caligari (1920), Cesare the sleepwalker is generally calm, except when he attempts to kill a resistant young lady. Lady Macbeth starts with a quiet sleepwalking episode and ends with shouting and crying in Macbeth (Wells, 1948; Polanski, 1971). In one sleepwalking episode in Sleepwalk with me (2012), the sleepwalker kicks a basket with his foot. Gestures are atypical (robot-like movements) in most silent movies and in some more recent movies (e.g., in Step Brothers, 2008; Eddy, the sleepwalking cannibal by Rodriguez, 2012). Clumsy or incongruous behavior is sometimes depicted (in Step Brothers, one places their mother's purse in the fridge while the other places a pillow in the oven) in contrast with accurate gestures in other cases (a character climbing a ladder, walking on a tightrope, stealing jewelry, or firing a gun). Sleep driving is observed in four instances, as in The Sleepwalker killing (1997), when one character realizes during his trial that he had been driving asleep for 40 miles and in Sleepwalker (Runneborg, 2000), when the hero drives under the influence of alcohol and drugs. Four sleepwalkers sing while sleeping, including Lady Macbeth who hums to herself (Welles, 1948). In Sleepwalker (Hochet, 2016), the sleepwalking girl sings ("Mr Sandman, bring me a dream") before slitting her throat, and in Slumber (2017), children sleep-sing in the dark. Other odd behaviors include committing a robbery $(\mathrm{N}=11)$, holding a candle in their hand $(\mathrm{N}=5)$, hiding in a cupboard $(\mathrm{N}=1)$, getting married $(\mathrm{N}=1)$, housekeeping $(\mathrm{N}=1)$, filling a basket with ashes and throwing them on a bed $(\mathrm{N}=1)$, getting dressed $(\mathrm{N}=1)$, dancing $(\mathrm{N}=1)$, and swimming $(\mathrm{N}=1)$. Most often, the episode ends when the sleepwalkers go back to bed, spontaneously or gently guided by someone else. They awake naturally or are awakened by someone else (police, director of the school, friend, dog). In a few instances, the sleepwalkers suddenly get up due to feeling pain, falling from the bed, bumping into an object, falling in water, being burned by hot water in the shower, or because they see a light source (train headlights, flashlight).

\subsection{Night terrors, sexsomnia, sleep-related eating disorder and sleep talking}

Night terrors are associated with sleepwalking in 6 movies, typically presented as a sleepwalker with raised chest and shouting, as in Nosferatu (Murnau, 1922). Parasomnia episodes including sexsomnia are encountered in 12 movies. Kissing (a spouse, stranger, neighbor or statue) is observed in 9 out of 12 movies. A female character has an orgasm while having an erotic dream in A lizard in a woman skin (Fulci, 1971), and is later suspected to have committed a crime while sleepwalking. In Benilde or the virgin mother (De Olivera, 1974), the main female 
character is pregnant but is unable to recall sexual intercourse. In Sleepwalking in Suburbia (Wright, 2017), Michelle walks to the parental bedroom of her neighbors, kisses the female neighbor, has sex with the male neighbor and gets pregnant. In In my sleep (2010), a male character has sex with his wife's best friend. A scene of parasomniac fellatio takes place in a plane in I'm so excited (2013). In Good manners (2018), the female lead has a engages in sensual acts with her housemaid while sleeping.

Five parasomnia episodes were associated with amnestic eating, drinking or preparing food. They included setting the table for breakfast in the middle of the night in Side effects (2013), cooking with entire eggs (shells included) in Slumber (2017), and switching on the stove and heating some milk in Sleepwalking in Suburbia (2017). In Good manners (2018), a pregnant mother eats raw meat in large quantities from the fridge and devours a cat, and in Eddy the sleepwalking cannibal (2012), sleepwalking episodes are associated with cannibalism.

Sleep talking is noted in 17 movies, most often including mumbles, but a few sleepwalkers speak with clear voices and meaningful sentences, sometimes aggressively. For example, in Nosferatu (1922), Nina shouts "Jonathan! Jonathan! Listen to me! I must go and meet him", and Lady Macbeth confesses her crime (Welles, 1948). In Neel Kamal (Maheshawari, 1968), the sleepwalking heroine answers to the lover from her past life: "No, no. Don't touch me, don't touch me". In Poltergeist (Hopper, 1982), the little girl dialogues with maleficent evils from the TV. In Sleepwalker (Hochet, 2016), the sleepwalker shouts "Simon, you're just an asshole", mumbles and then says "No, no, stop, don't touch me". Sleepwalkers laugh with an evil laugh in Macbeth (Welles, 1948), Slumber (2017) and City of pirates (1984).

\subsection{Sleep mentation associated with sleepwalking episodes}

Several sleepwalkers recognize having had a nightmare on the next morning, often a recurring nightmare $(\mathrm{N}=14)$. Some characters explicitly mention that they had a dream $(\mathrm{N}=6)$. Eventually, dream walking is suggested by a physician to explain the sleepwalking episodes (e.g., in Heidi, by Comencini in 1952: "She dreams of her mountains"). In Sleepwalk with me (2012), a dream or nightmare is depicted in most sleepwalking episodes. Usually, sleepwalkers have no recollection of the episodes. For instance, they ask where they are. There are two exceptions. In The sleepwalker killing (1997), the sleepwalker remembers his mother-in-law's face (as he killed her during the episode) and the feeling that his children were in danger. In Slumber (2017), the father engages in violent behavior against a doctor, thinking or dreaming that she will hurt his children. 


\subsection{Triggers}

Main triggers depicted explicitly or implicitly include stress, sleep debt and substance intake (alcohol, drug) during the preceding days (Table 2). Drug names seem to refer to common medications, including Halcium (probably Halcion ${ }^{\circledR}$ ) and Ablixa (probably Eblixa ${ }^{\circledR}$ ). Snoring and sleep apnea, which have been mentioned as triggers of sleepwalking, were not encountered before or during human sleepwalking in movies, and no obese sleepwalkers were depicted. In contrast, humans and animals (dog, bear, mouse, duck, sheep) sleepwalking in 13/22 cartoons snored (possibly as a mean to depict the fact that they were sleeping) and some continued to snore during the sleepwalking episode (e.g., Mickey Mouse snored during sleepwalking). However, no apnea or crescendo snoring (suggestive of hypopnea) as triggers of sleepwalking were found.

\subsection{Consequences of sleepwalking episodes on the screen}

In several movies, the sleepwalking episode is associated with injuries to oneself, including pseudo-suicide which results in death in three movies (Table 3). More frequently, sleepwalkers are placed at high risk of falling or injuring themselves due to misuse of objects. In general, the sleepwalkers do not hurt themselves, are prevented from hurting or protected at the last minute by intervening individuals. Sleepwalkers injure or kill $(\mathrm{N}=8)$ or attempt to murder $(\mathrm{N}=3)$ other characters. Murder suspicion is featured in five additional movies. The social consequences of sleepwalking include being excluded (from school, army or navy or from their family), imprisoned, placed in an asylum, and exposed to mockery. Personal consequences include feeling ashamed and developing insomnia. Positive consequences of sleepwalking are also featured, including falling in love $(\mathrm{N}=4)$, catching burglars (Pimple's Midnight Ramble by Evans, 1903), saving a child from a lofty window edge (The sleepwalker by Le Saint, 1922), as well as capturing the real criminal and becoming a hero (Early to bed by Mc Leod, 1936).

\subsection{Medical management}

Clinicians are generally medical doctors $(N=15)$, sleep specialists $(N=7$; first appearing as experts in The Sleepwalker killing in 1997), psychiatrists $(\mathrm{N}=2)$, psychoanalysts $(\mathrm{N}=2)$, psychologists $(\mathrm{N}=3)$ or a gynecologist and even a demonologist. A medical lesson on sleepwalking is sometimes given, which can be considered mostly accurate, according to diagnostic criteria, however the idea that the subconscious is responsible for the behavior is frequently observed. The idea that one should not wake up sleepwalkers because it could kill them is frequent. In Phenomena (1985), Jessica benefits from an electroencephalography, 
whereas in 5 other movies a video-polysomnography is performed. Most of the time, the doctor analyzes live polysomnography during the night. Some counterstrategies are suggested and implemented by the sleepwalkers or their family, including drugs (benzodiazepines and some unspecified medicines), mechanical disposals to protect the sleeper as well as prevent ambulation and wandering, and suggestions to follow the repressed desires of the sleepwalker (Table 4). Most doctors recommend resting, avoiding stress, and supervising the sleeper.

\subsection{Sleepwalking in cartoons}

Twenty-two cartoons were investigated (starting from Popeye: A Dream Walking, from the Fleischer Studios in 1934). Twelve cartoons feature a sleepwalking animal, including two dogs (Pluto and Goofy), a bear, a sheep, two ducks (Donald duck and a duck in The Tom and Jerry show), Woody Woodpecker, Bugs Bunny, the horse Spark Plug, a ram, a snail and an undetermined animal. Eyes are more often closed in cartoons (19/21 [90\%] than in movies (6/65 [9\%], P < 0.0001). Sleepwalkers in 16/21 (76\%) cartoons more often present outstretched arms than in 13/65 (20\%) movies (P < 0001). Incongruous and extraordinary actions include tightrope walking $(\mathrm{N}=6)$, climbing (building, trees), walking on the ceiling, eating a house (in A Hoss Kin Dream), opening the lock of a prison door, running away from prison, opening a safe $(\mathrm{N}=2)$ (in the Daltons), wearing a boot as a hat (in Donald Duck), walking with a bucket on the head, building a tunnel ( $\mathrm{N}=2$ as in Woody Woodpecker), placing video tapes as dominoes, putting a dog on small cars, destroying a museum, eating jewelry (in the Simpsons), sleep eating $(\mathrm{N}=4)$, and kissing $(\mathrm{N}=2)$. Dangerous behaviors include sleep driving, walking on a ceiling, climbing, tightrope walking, balancing at the top of a cliff, setting one's bed on fire (Inspector Gadget), falling, risking of being robbed or eaten (being in a lion's cage, at the enemy's mercy, as in Tom \& Jerry), drowning, being manipulated by children (Simpsons), and being run over by a car.

\section{Discussion}

\subsection{From burlesque to tragedy and horror}

The production of the 87 movies (and 21 cartoons) portraying sleepwalkers from the onset of motion picture production in 1900 to 2019 had two peaks, in the 1910s and 2010s. One third of movies featuring sleepwalkers belong are comedies, predominantly before $(51 \%)$ than after (14\%) 1960, especially during the burlesque movie era (before World War I). During this period, the public was fascinated by duality and unconscious automatisms of the body. 
Experimental psychology, hysteria and neurological cases pictured by Charcot and Gilles de la Tourette, as well as psychiatric theories gave the Parisian cabaret and early film comedy a new repertoire of movements, grimaces, tics and gestures [18]. It should be noted that silent movies first took place in fairs, between phantasmagoric shows, exhibits of individuals with physical diseases, hypnosis sessions (including more or less rigged psychic experiences) and other shows, making sleepwalking on the screen a particularly famous topic. In comedies and cartoons, sleepwalking seems to inspire directors as an archetypical way to use the mechanisms of laughter analyzed by Bergson [19], including absent-minded characteristics (e.g., wearing a hat combined with pajamas or eating jewelry), incongruous and graceless movements, rigid facial features, and socially awkward behaviors (e.g., walking outside in pajamas). The fact that most sleepwalkers do not speak but display facial emotions also make them suitable for the silent cinema and cartoons.

These laugh-inducing sleepwalkers become less present after 1960, when sleepwalking is more often represented as a medical disorder or a frightening topic in dramas, thrillers and horror movies. Indeed, what makes us laugh can also evoke fear, using bizarreness and stiffness as similar emotion triggers. The power of violence in sleepwalkers evolves over the course of the century with a more frequent negative depiction, from a "worrying strangeness" feeling to the character of the "murderer sleepwalker" and the "possessed sleepwalker", which is not genuine sleepwalking but rather a sleep-related dissociative disorder [17]. This character was featured on screen early on by the iconic character of Cesare the sleepwalker in The Cabinet of Dr Caligari (1920), considered as the first horror movie in history, at a time when séances and paranormal beliefs were influent [20]. The cinematographic motifs of the mise-en-scene aimed at inducing dread are recurrently used. Episodes begin at nighttime and often convey a thrilling atmosphere created by a silent, dark setting and a dim source of light, often used to induce typical jump scare effects (e.g., creaking of a door, or a sleepwalker suddenly appearing in a white nightdress as a ghost). Dangerous sleepwalking behaviors, including homicide, falls and even cannibalism are recurrent frightening topics. The sudden change of personality of the sleepwalkers (especially when they are family members) to the point of being out of control (suggesting evil possession, double personality, and schizophrenia) and the change in facial expression (bugling eyes) may recall transformation into a monster. Similarities can be found in these films between sleepwalkers, who are between wakefulness and sleep, and the walking dead and zombies, who are between life and death.

Apart from these amusing and frightening aspects, a more poetic approach of directors is to portray sleepwalkers as dreamers escaping their daily fate during the night, in a show of 
freedom. The Prince of Hamburg sleepwalks to escape facing war. In When father goes away on business, the little boy sleepwalks to escape his parent's fights. Neel Kamal walks during the night when called on by her forbidden love. Here, the implicit mechanism used by the directors is the psychoanalytic concept that one would express a resurgence of repressed (hate or love) instincts through dreams (in this case enacted).

\subsection{The epidemiology of sleepwalking on the silver screen}

In accordance with the epidemiology of adult sleepwalking in the general population [21, 22] and in hospital cohorts [23-25], sleepwalking characters in movies are mostly young adults. Surprisingly, children with sleepwalking are quite rarely portrayed in movies, whereas sleepwalking is more frequent in children than in adults in epidemiology [3].

There is a predominance (two thirds) of women in sleepwalking movies, when nocturnal wandering equally affects men and women in epidemiological studies [22]. The director may have chosen to portray women in movies as an opportunity to show female bodies eroticized in white, transparent nightgowns, or to illustrate female "vulnerability". A similar trend towards portraying affected women more than men is observed in the representation of epilepsy in movies [14].

Surprisingly, familial cases of arousal disorders are rare $(3 \%)$ on the silver screen, whereas a family history is reported by one third of subjects in epidemiology [22] and in half of patients in hospital series [23]. As many as $23 \%$ of sleepwalker characters have psychopathologic comorbidities in movies, in contrast with the majority of adult sleepwalkers having no significant psychopathology [26]. This representation may illustrate the common (and false) belief that somnambulism has a psychopathologic background or can be a symptom of a psychiatric disease. Alternatively, it may be the director's choice to render the character's personality more fearful and complex.

\subsection{Semiology of behaviors}

In movies, sleepwalking episodes occur more often the middle of the night and exceptionally the morning, whereas in medical exploration, the main episode most often occurs in the first third of the night. Filming in complete darkness is impossible, unless one uses an infrared light as in sleep laboratories. To circumvent this problem, the Day for night procedure has been in use since silent movies. It consists in filming during the day using an underexposed film or by darkening the film during post-production with a blue tint. 
The main triggers of episodes in the movies considered (explicitly reported in 26\% movies) correspond to those found in the medical literature, including stress conditions during the previous days, sleep debt, alcohol, as well as drug or substance intake [23, 24, 27, 28]. Selfinjuries, pseudo-suicide and high risk of falling are often portrayed, and injuries (or risk of injuries) to others and even homicide are found in 11 movies. In contrast to documented medical cases $[29,30]$, there is no rape committed by sleepwalkers in movies portraying sexsomnia (although it is implicitly suggested in two movies that the sleepwalking woman has been raped) but some sleepwalkers do enter someone else's bed.

\subsection{Misdiagnosis of sleepwalking}

As many as one third of movies picturing so-called sleepwalking episodes did not fulfill the criteria of genuine, medical sleepwalking [2], but rather illustrated differential diagnoses. The most frequent misdiagnosis was SRDD or psychogenic parasomnia, which could apply by proxy to magnetic- or hypnosis-induced amnestic behaviors and to nocturnal behaviors as ghost possessions. In both instances, the nightwalkers did not act on their own will, but instead had their mind controlled by another entity. This serves an artistic purpose, whereas genuine SRDD may occur in patients with a psychiatric neurotic condition, often attracting the attention of families and physicians by "possession-like" behaviors (large body, shoulder and hip movements with closed eyes when lying in bed, despite being awake) [17]. One may wonder in these cases whether on-screen portrayals of ghost possessions may influence these behaviors. Malingering (masqueraded sleepwalking) was pictured in around $10 \%$ of movies, mostly for masking love or murder purposes. In these cases, the director clearly indicated to the audience that sleepwalking was feigned. REM sleep behavior disorder corresponds to enacted dreams in REM sleep by lack of normal muscle atonia, and is easily distinguished from sleepwalking in movies because it usually affects elderly, who have their eye closed, fight in their bed and do not wander [31]. Despite sleepwalkers sometimes reporting brief (and rarely more complex) visual dream contents, as well as enactments of the content of these N3 dreams and nightmares [4, 32-34] as patients with REM sleep behavior disorder are prone to doing, this notion that one "dream walks" is quite recent in sleep medicine (as is the idea that one does dream in N3 and not only in REM sleep), to the point that some physicians may still mistake dream/sleep walking with REM sleep behavior disorder. Mike Birbiglia's 2017 film (Sleepwalk with me), who as a director depicts his own case, seeks medical advice, and eventually receives the diagnosis of RBD instead of sleepwalking (against compelling evidences that he sleepwalks), is an interesting illustration of this false belief. 
4.5 The outstretched arms and closed eyes posture As many as $20 \%$ of movies and $76 \%$ of cartoons portray sleepwalkers with outstretched arms. This feature corresponds to the popular representation of sleepwalking, as displayed in several works of art [11], including paintings (The sleepwalker by Mucha, 1885; The sleepwalking dancer by Von Resnicek, 1906), sculptures (The sleepwalker by de Miller, 1983; The sleepwalker by Matelli, 2014; The sleepwalkers by Sechas, 2002), ballets (The night shadow by Balanchine, 1946; Café Müller, by Bausch, 1978) and theatre plays. Arms are stiffly held out or outstretched laterally. Hands may be raised up vertically, horizontally or downwards. The origin of this tonic arm posture is unknown. One may speculate that it shares similarities with the posture of blind persons protecting themselves from being hurt when walking, hence there is a certain coherence in associating outstretched arms and closed eyes. Alternatively, it may be a contamination of the posture used by hypnotists in the beginning of the $20^{\text {th }}$ century. In a common representation, they induce magnetic somnambulism (hypnotic trance) by sending a fluid through their outstretched hands. In the recent field of medical hypnosis, hypnotherapists do not "send" something with their hand, but they do use a subject's arm stiffness to induce and verify the hypnotic state, as described in most suggestibility and induction scales [35]. Of interest, zombies in movies have outstretched arms, but their hands are placed in a catching position with fingers spread, as if wanting to grab people [36]. In the script of the movie I Walked With the Zombie by J. Tourneur (1943), zombie wandering is described as "A white-robed female figure comes out from under the stairs, walking slowly, her movements drift-like as if walking in deep sleep”, illustrating some commonalities between zombies and sleepwalkers. From a practical, directors' point of view, the outstretched arm posture has the major visual advantage that the public to easily recognizes that a character is sleepwalking.

Beside this unrealistic posture, robot-like, saccadic movements are also portrayed in movies featuring sleepwalking, more often in comedies, in sharp contrast with fluid movements in medical sleepwalking [37]. Here, one may notice the similarity with movements of mechanic automatons and dolls, first created by de Vaucanson in $18^{\text {th }}$ century [38]. In addition to posture, an abnormal, saccadic behavior may also help the spectator identify the affected character. In $9 \%$ of movies and $90 \%$ of cartoons, sleepwalkers are represented with eyes closed. Although medical sleepwalkers have eyes open, especially when walking [1,7], it seems that Shakespeare was better informed in 1606 than contemporary film-makers: in the sleepwalking scene in Macbeth, the doctor claims that "Her eyes are open but she cannot see". However, as 
well as above, closed eyes may be used as a cinematographic visual signature depicting that a character is asleep.

\subsection{General conclusion}

Although it spans a century, this series of movies is certainly not exhaustive, and mostly limited to Western movies released in the United States and Europe. For a few movies, we only found scripts (some 1900-1910 movies had been lost), leading to incomplete information. These two limitations being acknowledged, this work brings several new findings. Within one century, sleepwalking on the silver screen has progressively evolved from burlesque presentation (the caricature being a young beautiful woman dressed in a transparent white nightgown, wandering with eyes closed and outstretched arms) towards a dangerous and sometimes medical presentation, possibly mirroring medical research on sleepwalking with some delay. In popular culture, sleepwalking is not considered as a disease and is often a neglected condition. Consequently, directors can still afford to freely deal with this topic and use parody and stereotypes, whereas they would not easily caricature a stroke or Parkinson's disease in their movies.

The development of an accurate medicalization (now featuring sleep laboratories, polysomnography, and medical advices, including forensic expertise) on screen helps to consider sleepwalking as an established sleep disorder. Film exerts a huge power on collective imagination, but as with any artwork, it does not necessarily need to make a true-to-life portrait. Directors may choose to represent unrealistic forms of somnambulism, as part of their creative art. On the other hand, popularizing false stereotypes can have deleterious effects. Directors could benefit from the advice of sleep specialists if their purpose is to portray a real disease. Conversely, educational programs including several emblematic movies may enhance the clinical proficiency of future physicians in sleep disorders semiology.

Acknowledgements : the authors thank Emmanuel Siety (Université Sorbonne Nouvelle, Institut de recherche sur le cinéma et l'audiovisuel) for his thoughtful remarks on the manuscript.

Founding: This research did not receive any specific grant from funding agencies in the public, commercial, or not-for-profit sectors 


\section{References}

[1] Barros A, Uguccioni G, Salkin-Goux V, Leu-Semenescu S, Dodet P, Arnulf I. Simple behavioral criteria for the diagnosis of disorders of arousal. J Clin Sleep Med 2020;16:121-8.

[2] American Academy of Sleep Medicine. The international Classification of Sleep Disorders, 3rd edition. Darien, IL: American Academy of Sleep Medicine; 2014

[3] Arnulf I. Sleepwalking. Curr Biol 2018;28:R1288-9.

[4] Oudiette D, Leu S, Pottier M, Buzare MA, Brion A, Arnulf I. Dreamlike mentations during sleepwalking and sleep terrors in adults. Sleep 2009;32:1621-7.

[5] Rocha AL, Arnulf I. NREM parasomnia as a dream enacting behavior. Sleep medicine 2020;75:103-5.

[6] Derry C, Harvey A, Walker M, Duncan J, Berkovic S. NREM arousal parasomnias and their distinction from nocturnal frontal lobe epilepsy: A video EEG analysis. Sleep 2009;32:1637-44.

[7] Mwenge B, Brion A, Uguccioni G, Arnulf I. Sleepwalking: long-term home video monitoring Sleep medicine 2013;14:1226-8.

[8] Edelman N. Le somnambulisme magnétique: les enjeux d'une mise à la marge (Première moitié du XIXe siècle en France). . L'Homme et la société 2008;167-168169:85-100.

[9] Lorusso L, Franchini AF, Porro A. Opera and neuroscience. Prog Brain Res 2015;216:389-409.

[10] Finger S, Sironi VA, Riva MA. Somnambulism in Verdi's Macbeth and Bellini's La Sonnambula: opera, sleepwalking, and medicine. Prog Brain Res 2015;216:357-88.

[11] Umanath S, Sarezky D, Finger S. Sleepwalking through history: medicine, arts, and courts of law. J Hist Neurosci 2011;20:253-76.

[12] Handley S. Deformities of Nature: Sleepwalking and Non-Conscious States of Mind in Late Eighteenth-Century Britain. J Hist Ideas 2017;78:401-25.

[13] Cody M. Sleepwalking into the Nineteenth Century: Charles Brockden Brown's "Somnambulism. Journal of the Short Story in English 2002;39:41-55.

[14] Baxendale S. Epilepsy at the movies: possession to presidential assassination. Lancet Neurol 2003;2:764-70.

[15] Wijdicks EF, Wijdicks CA. The portrayal of coma in contemporary motion pictures. Neurology 2006;66:1300-3.

[16] Iranzo A, Schenck CH, Fonte J. REM sleep behavior disorder and other sleep disturbances in Disney animated films. Sleep medicine 2007;8:531-6.

[17] Schenck C, Cramer Borneman M, Klapish N, Eiser A. Sleep-related (psychogenic) dissociative disorders as parasomnias associated with a psychiatric disorder: update on reporeted cases. J Clin Sleep Med 2021;17:803-10.

[18] Gordon R. From Charcot to Charlot: Unconscious Imitation and Spectatorship in French Cabaret and Early Cinema. Critical Inquiry 2001;27:515-49.

[19] Bergson H. Le Rire : essai sur la signification du comique. Paris: Alcan Ed.; 1924

[20] Cuchet G. Le retour des esprits, ou la naissance du spiritisme sous le Second Empire. . Revue d'histoire moderne et contemporaine 2007;54:74.

[21] Ohayon MM, Guilleminault C, Priest R. Night terrors, sleepwalking, and confusional arousals in the general population: their frequency and relationship to other sleep and mental disorders. J Clin Psychiatry 1999;60:268-76. 
[22] Ohayon MM, Mahowald MW, Dauvilliers Y, Krystal AD, Leger D. Prevalence and comorbidity of nocturnal wandering in the U.S. adult general population. Neurology 2012;78:1583-9.

[23] Lopez R, Jaussent I, Scholz S, Bayard S, Montplaisir J, Dauvilliers Y. Functional impairment in adult sleepwalkers: a case-control study. Sleep 2013;36:345-51.

[24] Arnulf I, Zhang B, Uguccioni G, Flamand M, Noël de Font-Réaux A, Leu-Semenescu S, et al. A scale for assessing the severity of arousal disorders. Sleep 2014;37:127-36.

[25] Carrillo-Solano M, Leu-Semenescu S, Golmard JL, Groos E, Arnulf I. Sleepiness in sleepwalking and sleep terrors: a higher sleep pressure? Sleep medicine 2016;26:549.

[26] Labelle MA, Desautels A, Montplaisir J, Zadra A. Psychopathologic correlates of adult sleepwalking. Sleep medicine 2013;14:1348-55.

[27] Stallman H, Kohler M, White J. Medication induced sleepwalking: A systematic review. Sleep Med Rev 2018;37:105-13.

[28] Pressman M. Factors that predispose, prime and precipitate NREM parasomnias in adults: Clinical and forensic implications. Sleep Medicine Rev 2007;11:5-30.

[29] Schenck $\mathrm{CH}$. Update on sexsomnia, sleep related sexual seizures, and forensic Implications. NeuroQuantology 2015;13:518-41.

[30] Dubessy A, Leu-Semenescu S, Attali V, Maranci J, Arnulf I. Sexsomnia: a specialized Non-REM parasomnia. Sleep 2017; In press.

[31] Schenck CH, Mahowald MW. REM sleep behavior disorder: clinical, developmental, and neuroscience perspectives 16 years after its formal identification in SLEEP. Sleep 2002;25:120-38.

[32] Schenck $\mathrm{CH}$, Mahowald MW. A polysomnographically documented case of adult somnambulism with long-distance automobile driving and frequent nocturnal violence: parasomnia with continuing danger as a noninsane automatism Sleep 1995;18:765-72.

[33] Schenck C. Lost Paradox: Extreme-Nights. LLC, editor: 2005

[34] Uguccioni G, Golmard JL, de Fontreaux A, Leu-Semenescu S, Brion A, Arnulf I. Fight or flight? Dream content during sleepwalking/sleep terrors vs rapid eye movement sleep behavior disorder. Sleep medicine 2013;14:391-8.

[35] Bowers KS. The Waterloo-Stanford Group C (WSGC) scale of hypnotic susceptibility: normative and comparative data. Int J Clin Exp Hypn 1993;41:35-46.

[36] Schefer O. Figures de l'errance et de l'exil. Cinema, art et anthropologie., Paris: Rouge Profond; 2013

[37] Siclari F, Valli K, Arnulf I. Dreams and nightmares in healthy adults and in patients with sleep and neurological disorders. Lancet Neurol 2020;19:849-59.

[38] Wood G. Living Dolls: A Magical History Of The Quest For Mechanical Life. The Guardian. 2002. 
Table 1- Movies with depicted sleepwalking

\begin{tabular}{|c|c|c|c|c|}
\hline Title & Director & Year & Country & Genre \\
\hline The somnambulist & A. Collins & 1903 & USA & Fantasy \\
\hline The greedy girl & L. Fitzhamon & 1908 & UK & Fantasy \\
\hline The sleepwalker & T. Bouwmeester & 1909 & USA & Thriller \\
\hline The sleepwalking hussar [Le hussard somnambule]* & Pathé Frères & 1910 & France & Comedy \\
\hline Eloi wants to learn to swim [Eloi veut apprendre à nager]* & M. Carré & 1910 & France & Comedy \\
\hline The sleepwalker & V.D. Brooke & 1911 & USA & Comedy \\
\hline Bébé sleepwalker [Bébé somnambule]* & L. Feuillade & 1911 & France & Comedy \\
\hline Pénard is superstitious [Pénard est supersticieux]* & Pathé Films & 1912 & France & Comedy \\
\hline The lost necklace & Pathé Films & 1912 & USA & Drama \\
\hline A night of peril & B. Haldan & 1912 & USA & Drama \\
\hline The mystery of Mr Marks & W. Buckland & 1914 & UK & Thriller \\
\hline Boireau sleepwalker [Boireau somnambule]* & A. Deed & 1915 & France & Comedy \\
\hline Somnambulism and chloroform [Somnambulisme et chloroforme]* & L. Cazalis & 1915 & France & Comedy \\
\hline The fatal ring & G. Brackett Seitz & 1918 & USA & Thriller \\
\hline The doll [Die puppe] & E. Lubitsch & 1919 & Germany & Comedy \\
\hline High and dizzy & H. Lloyd & 1920 & USA & Comedy \\
\hline The cabinet of Dr. Caligari [Das cabinet des Dr. Caligari] & R. Wiene & 1920 & Germany & Horror \\
\hline The sleepwalker & E. LeSaint & 1922 & USA & Drama \\
\hline Nosferatu [Nosferatu: eine Symphonie des Grauens] & F.W. Murnau & 1922 & Germany & Horror \\
\hline The gay retreat & B. Stoloff & 1928 & USA & Comedy \\
\hline The haunted house & B. Christensen & 1928 & USA & Comedy \\
\hline The pearl [La perle]* & H. d'Ursel & 1929 & Belgium & Comedy \\
\hline Sleep my love & D. Sirk & 1948 & USA & Thriller \\
\hline Macbeth & O. Welles & 1948 & USA & Drama \\
\hline The sleepwalker [Boniface somnambule] & M. Labro & 1951 & France & Comedy \\
\hline Ensemble for somnambulists & M. Deren & 1951 & USA & Experimental \\
\hline Half angel & R. Sale & 1951 & USA & Comedy \\
\hline Heidi & L. Comencini & 1952 & Swiss & Drama \\
\hline Carmela is a doll [Carmela è una bambola] & G. Puccini & 1958 & Italia & Comedy \\
\hline Viridiana & L. Bunuel & 1961 & Spain & Drama \\
\hline Don't look now... We're being shot at! [La grande vadrouille] & G. Oury & 1966 & France & Comedy \\
\hline Neel Kamal & R. Maheshwari & 1968 & India & Drama \\
\hline Count Dracula & J. Franco & 1970 & USA & Horror \\
\hline A lizard in a woman's skin [Una lucertola con la pelle di donna] & L. Fulci & 1971 & Italia & Thriller \\
\hline Macbeth & R. Polanski & 1971 & USA & Drama \\
\hline Benilde or the virgin mother [Benilde ou a virgem mãe] & M. de Oliveira & 1974 & Portugal & Drama \\
\hline Nosferatu the vampyre & W. Herzog & 1979 & Germany & Horror \\
\hline Poltergeist & T. Hooper & 1982 & USA & Horror \\
\hline City of pirates [La ville des pirates] & R. Ruiz & 1984 & F-Portugal & Drama \\
\hline Sleepwalker & S. Logan & 1984 & USA & Horror \\
\hline When father was away on business [Otac na službenom putu] & E. Kusturica & 1985 & Yugoslavia & Drama \\
\hline
\end{tabular}


Creepers [Phenomena]

D. Argento 1985

The sleepwalker killing

J. Cosgrove

1985
1997

M. Bellochio

1997

Sleepwalker

J. Runeborg

2000

Donnie Darko

R. Kelly

2001

An adventure [Une aventure]*

X. Giannoli

2005

Silent hill

C. Gans

2006

My Winnipeg

G. Maddin

2007

Stepbrothers

Caligari and the sleepwalker

A. McKay

J. Tellez

2008

Dream [Bi-Mong]

K. Ki Duk

2008

In my sleep

A. Wolf

2008

Sleepwalker in 3D [夢遊 3D]

O. Pang

2010

Eddie, the sleepwalking cannibal

B. Rodriguez

2011

Sleepwalker [Сомнамбула]

A. Iakovlev

2012

The towrope [La sirga]

W. Vega

2012

Side effects

The conjuring

S. Soderbergh

2012

J. Wan

2013

I'm so excited [Los amantes pasajeros]

P. Almodovar

2013

The sleepwalker

M. Fastvold

2013

Honeymoon

Sleepwalker [Somnambule]*

L. Janiak

2014

T. Hochet

2014

Marie and the castaways [Marie et les naufragés]*

S. Betbeder

2016

Sleepwalk with me

M. Birbiglia

2016

Sleepwalker

Sleepwalker

S. Loch

2017

Sleepwalking in Suburbia

E. Lester

2017

Slumber

Sleepwalker

A. Wright

2017

J. Hopkins

2017

A. Cooley

2017

Love standing up [L'Amour debout]*

M. Dacheux

2017

Good manners [As boas maneiras]

J. Rojas

2018

Brightburn

D. Yavoresky

2018

F: France, S: South; [original title]

Italia

USA

Italia

Sweden

USA

France

F-Canadian

Canada

USA

Venezuela

S. Korea

USA

China

Canada

Russia

Colombia

USA

USA

Spain

Norway

USA

France

France

USA

Australia

USA

Canada

USA

Canada

France

Brazil

USA
Horror

Drama

Drama

Thriller

Horror

Drama

Horror

Drama

Comedy

Experimental

Thriller

Thriller

Thriller

Horror

Thriller

Drama

Thriller

Horror

Comedy

Drama

Horror

Drama

Comedy

Comedy

Horror

Thriller

Drama

Horror

Horror

Comedy

Horror

Horror 
Table 2 - Triggers of the depicted sleepwalking episodes in movies

\begin{tabular}{|c|c|}
\hline Trigger & Movies \\
\hline \multicolumn{2}{|l|}{ Stress } \\
\hline Her fiancé is in danger & Nosferatu (1922) \\
\hline Remorse & Macbeth (1948) \\
\hline Nostalgia & Heidi (1952) \\
\hline Perspective of getting married & $\begin{array}{l}\text { Half Angel (1951); Carmela é una } \\
\text { bambola (1958) }\end{array}$ \\
\hline Parents quarrel & When father was away on business (1985) \\
\hline Gambling debts & The sleepwalker killing (1997) \\
\hline Anxiety & Sleepwalker by Runeborg (2000) \\
\hline Divorce & Dream (2008) \\
\hline Post-traumatic stress (her village was burnt) & The Towrope (2012) \\
\hline Husband sent to jail, stress after a marital dispute & Side effects (2013) \\
\hline Honeymoon trip & Honeymoon (2014) \\
\hline Love break & Sleepwalker by Hochet (2016) \\
\hline Pregnancy attempts after a miscarriage & Sleepwalking in suburbia (2017) \\
\hline \multicolumn{2}{|l|}{ Sleep deprivation } \\
\hline Slept in the sofa, bad sleep & The sleepwalker killing (1997) \\
\hline Shift work & Marie and the castaways (2016) \\
\hline Several short nights due to his job & Sleepwalk with me (2017) \\
\hline \multicolumn{2}{|l|}{ Alcohol, drugs and substances intake } \\
\hline Alcohol & Casey dreams that he is a sleepwalker (1904) \\
\hline A powder poured by her husband in a chocolate cup & Sleep my love (1948) \\
\hline Hypnotic pills given by her husband & I'm so excited (2013) \\
\hline Ablixa, an antidepressant prescribed by a psychiatrist & Side effects (2013) \\
\hline A combination of alcohol and Halcium & Sleepwalker by Runeborg (2000) \\
\hline Mundane alcohol intake & Sleepwalker by Logan (1984) \\
\hline
\end{tabular}


Table 3 : Consequences of the depicted sleepwalking

\begin{tabular}{ll}
\hline Consequences & Movies \\
\hline Death & The mystery of Mr. Marks (1914); Sleepwalker (2016); Slumber \\
Falling from roof, slits his & $(2017)$ \\
throat &
\end{tabular}

\section{Self-injury}

Falling, car accident, selfmutilation, bangs her head

\section{Risk of self-injury:}

Risk of falling when they step or jump over the window, walk or run on guardrail, roofs, or along a cliff, risk of being crashed on railways, of having an accident when sleep driving

\section{Homicide}

Strangulation, stabbing, gun fire

\section{Risk of homicide or injury}

Holds a gun or a knife

\section{Suspicion of homicide}

\section{Amnestic sensual or sexual behavior}

Kisses, sensual relation, fellatio, orgasm, rape, suspected rape, amnestic intercourse

Eating inedible food
The somnambulist (1903); Casey dreams that he is a sleepwalker (1904); A very young lady (1941); An adventure (2005); Sleepwalker (2012); The conjuring (2013); Sleepwalk with me (2017)

The maid is a sleepwalker (1913); The doll (1919); High and dizzy (1920); Nosferatu (1922; 1979); The pearl (1929); A dream walking (1934); Sing sister sing (1935); A very young lady (1941); Sleep my love (1948); Boniface sleepwalker (1951); Carmela is a doll (1958); Neel Kamal (1968); City of pirates (1984); When father was away on business (1985); Phenomena (1985); Donnie Darko (2001); Silent hill (2006); Dream (2008); In my sleep (2010); Marie and the castaways (2016); Sleepwalker (2017, by Loch); Sleepwalker (2017, by Leister); Love standing up (2018); Good manners (2018)

The mystery of Mr. Marks (1914); The Cabinet of Dr Caligari (1920); City of pirates (1984); Sleepwalker (1984); The Sleepwalker Killing (1997); An adventure (2005); Eddie the sleepwalking cannibal (2012); Side effects (2013); Brightburn (2019)

The sleepwalking hussar (1910); Sleep my love (1948); Viridiana (1961); Sleepwalker (2000); Stepbrothers (2008); Slumber (2017); Good manners (2018)

A lizard in a woman skin (1971); Dream (2008); In my sleep (2010); Sleepwalker in 3D (2011); Sleepwalker (2016)

Half angel (1951); The sleepwalker (1951); Carmela is a doll (1958); Count Dracula (1970); Lizard in a woman skin (1971); Benilde or the virgin mother (1974); In my sleep (2010); I'm so excited (2013); Honeymoon (2014); Marie and the castaways (2016); Sleepwalking in suburbia (2017); Good manners (2018)

Eddie the sleepwalking cannibal (2012); Good manners (2018) 
Raw meat, a cat, humans

\section{Exclusion}

from school

Bébé sleepwalker (1911); Phenomena (1985)

from army

from their family

The gay retreat (1928)

Placed in jail

Neel Kamal (1968); Benilde or the virgin mother (1974)

Placed in asylum

The sleepwalking hussar (1910)

Abducted

Phenomena (1985)

Shame and mockery

A night of peril (1912); The sleepwalker (1909); Dracula (1931)

Bébé sleepwalker (1911); Phenomena (1985); Neel Kamal (1968);

Donnie Darco (2001); Sleepwalking in Suburbia (2017)

Accusation of theft

Insomnia

The Sleepwalker (1911)

Half Angel (1951); Marie and the castaways (2016)

Became a hero

Pimple's midnight ramble (1913); The Sleepwalker (1922); Early to bed (1936)

Found love

Arsene Lupin (1932); Carmela is a doll (1958); Half Angel (1961;

Don't look now... We're being shot at! (1966) 
Table 4 - Management of depicted sleepwalking suggested in movies

\begin{tabular}{|c|c|c|c|}
\hline Treatment & Counsellor & Beneficial & Movie \\
\hline \multicolumn{4}{|l|}{ Drugs and calming substances } \\
\hline Calming plants, rest & Physician & No & Sleep my love (1948) \\
\hline Medicine bottle & Physician & No & Neel Kamal (1968) \\
\hline Pills & Sleep specialist & No & The Sleepwalker killing (1997) \\
\hline Pills (for associated hallucinations) & Psychiatrist & No & Donnie Darko (2001) \\
\hline Pills & Psychiatrist & No & Side effects (2013) \\
\hline Pills (in the evening) & Sleep specialist & No & In my sleep (2010) \\
\hline Goat milk before sleep & Her uncle & Unknown & La Sirga (2012) \\
\hline Anxiolytics & Gynecologist & No & Good manners (2018) \\
\hline \multicolumn{4}{|c|}{ Mechanical protections and disposals against ambulation } \\
\hline $\begin{array}{l}\text { Door blocked with furniture, upper } \\
\text { bed protected with ribbons, asks his } \\
\text { dog to watch }\end{array}$ & $\begin{array}{l}\text { Personal } \\
\text { treatment }\end{array}$ & No & Without Love (1945) \\
\hline Bell on the wrist & His parents & No & $\begin{array}{l}\text { When father was away on business } \\
\text { (1985) }\end{array}$ \\
\hline $\begin{array}{l}\text { Coffee and loud music (to avoid } \\
\text { sleep), a water bucket on the door }\end{array}$ & $\begin{array}{l}\text { Personal } \\
\text { treatment }\end{array}$ & No & Half Angel (1951) \\
\hline Tacks on the floor & Family, friends & No & Carmela e una bambola (1955) \\
\hline “Always keep an eye on her" & Physician & No & Neel Kamal (1968) \\
\hline "Don't let her sleep alone" & Physician & No & Phenomena (1985) \\
\hline Handcuffed to her partner & Unknow & Unknown & Dream (2008) \\
\hline $\begin{array}{l}\text { Handcuffed to bed, door blocked } \\
\text { with a chair }\end{array}$ & $\begin{array}{l}\text { Personal } \\
\text { treatment }\end{array}$ & No & In my sleep (2010) \\
\hline Nail planks to the window & His roommate & No & Eddie the sleepwalking cannibal (2012) \\
\hline Door blocked with a chair & $\begin{array}{l}\text { Personal } \\
\text { treatment }\end{array}$ & No & Sleepwalker by E. Lester (2017) \\
\hline Handcuffed to bed & $\begin{array}{l}\text { Personal } \\
\text { treatment }\end{array}$ & No & Sleepwalking in Suburbia (2017) \\
\hline Puts a second locker on the door & Sleep specialist & No & Sleepwalker by E. Lester (2017) \\
\hline $\begin{array}{l}\text { Sleeping in a sleeping bag with } \\
\text { mitten to avoid opening the zipper }\end{array}$ & Personal & Unknown & Sleepwalk with me (2017) \\
\hline \multicolumn{4}{|c|}{ One should follow the repressed desire of the sleepwalker } \\
\hline Gift of four fox dogs & Specialist MD & Yes & Qui a tué?(1926) \\
\hline "Only God can do something to her" & Family MD & Unknown & Macbeth (1948) \\
\hline Returning her home mountains & Family MD & Yes & Heidi (1952) \\
\hline $\begin{array}{l}\text { Calm, getting married, having } \\
\text { children }\end{array}$ & Physician & No & Neel Kamal (1968) \\
\hline $\begin{array}{l}\text { Go with her in the place mentioned } \\
\text { during her episode }\end{array}$ & Her parents & No & Silent hill (2006) \\
\hline $\begin{array}{l}\text { "Love! It will never stop until you } \\
\text { will be together" }\end{array}$ & Psychologist & Unknown & Dream (2008) \\
\hline Kills the evil that lives in him & Psychologist & No & Sleepwalker (Russian, 2012) \\
\hline
\end{tabular}


Supplementary Table - List of 22 cartoons featuring human and animal sleepwalkers

\begin{tabular}{llll}
\hline Title & Director & Year & Country \\
\hline Popeye the sailorman: "A dream walking" & Fleischer Studios & 1934 & USA \\
Pluto: "The Sleepwalker" & Studio Disney & 1942 & USA \\
Merrie Melodies: "The Unbearable Bear" & L.S. Studios & 1943 & USA \\
Donald Duck: "Sleepy Time Donald" & Disney Studios & 1947 & USA \\
Looney Tunes: "Water, water every hare" & C. Jones & 1952 & USA \\
Snuffy Smith and Barney Google: "A Hoss Kin Dream" & Paramount Cartoon & 1964 & USA \\
Looney Tunes: "Skyscraper Caper" & Studios & 1968 & USA \\
Popeye: "Popeye the sleepwalker" & A. Lovy & 1978 & USA \\
Bolek and Lolek: "Lolek sleepwalker" & G. Gordon & 1980 & Poland \\
[Bolek i Lolek: "Lolek lunatyk"]* & W. Nehrebeck & 1986 & USA \\
Inspector Gadget: "Bad dreams are made of this" & A. Heyward & 1999 & USA \\
The Woody Woodepecker show: "Sleepwalking Woody" & W. Lantz & 2007 & USA \\
The Simpsons: "Crook and Ladder" & L. Kramer & 2007 & USA \\
Shaun the sheep: "Sheepwalking" & J.P. Vine & 2008 & France \\
[Titeuf : «La Bouriflette somnambulique »] & C. Choquet & 2009 & USA \\
Ed, Edd n Eddy: "Sleepwalking Ed" & D. Antonucci & 2010 & France \\
The Daltons: "Averell, are you sleeping?" & C. Vaucelle & 2010 & Russia \\
[Les Daltons: "Averell, tu dors?"]* & I. Maximov & 2011 & USA \\
Smeshariki: "the sleepwalker" & K. Christides & 2013 & USA \\
Crime time: "Sleepwalker" & Disney Studios & 2013 & USA \\
Donald Duck: "Sleepwalkin’" & N. Cash & 2015 & Canada \\
Adventure time: "The vault" & T. Ushev & 2017 & USA \\
The sleepwalker [Sonámbulo] & J. Praytor & & \\
The Tom and Jerry show: "Sleepwalking Duck" & &
\end{tabular}




\section{Legend of the figures}

Figure 1 - Histogram of movies featuring sleepwalkers across time, per decade (from 1903 to 2020). Positive (comedy, in green) and negative (drama, thriller, horror, in dashed brown) emotional movies

Figure 2 - Sleepwalkers postures in movies. Upper panel: Jennifer sleepwalking in Phenomena, by D. Argento (1985), @Ronald Grant Archive / Alamy Stock Photo. Lower panel: Boniface and his children (familial sleepwalking), with upstretched arms in The sleepwalker by M. Labro (1951), (C Ronald Grant Archive / Alamy Stock Photo.

Figure 3 - Sleepwalker featured with wide open eyes: Cesare, in The cabinet of Doctor Caligari by R. Wiene (1920), (C) United Archives GmbH / Alamy Stock Photo. 